\title{
O CRISTO E A MULHER ADÚLTERA, DE RODOLFO BERNARDELLI E A ESCULTURA ITALIANA DO SÉCULO XIX
}

Maria do Carmo Couto da Silva ${ }^{1}$

\section{Resumo}

O tema central dessa comunicação é a análise da produção do escultor brasileiro Rodolfo Bernardelli (1852-1931) na Itália, no final do século XIX, enfocando especialmente a realização do grupo monumental em mármore Cristo e a mulher adúltera (1881-1884). Apesar da importância de Rodolfo Bernardelli no cenário artístico brasileiro, a sua trajetória ainda não foi estudada por completo. Percebendo a ausência de estudos nessa área, enfocamos o período de sua formação em nossa pesquisa de mestrado, concluída em 2005. O artista, que freqüentou a Academia Imperial de Belas Artes, na década de 1870, estudou em Roma por vários anos, onde também criou algumas de suas obras mais conhecidas. $\mathrm{Na}$ Itália, o jovem escultor foi aluno de Giulio Monteverde e manteve contato com a obra de destacados artistas como Vincenzo Gemito, Achille d'Orsi e Michetti. Em 1885, ele regressou ao Rio de Janeiro e expôs, em mostra individual, os trabalhos realizados no exterior, obtendo grande repercussão na imprensa e crítica cariocas e também na Academia. O seu grupo escultórico Cristo e a Mulher Adúltera, apresentado nessa mostra, tanto pelo tema como por sua ousada execução formal, revela o diálogo com a escultura italiana contemporânea. É esse aspecto da produção de Bernardelli, presente também em outras obras suas desse período, que faz com que o artista seja prestigiado em seu retorno da Europa e indica novas direções para a escultura no Brasil, no final do Segundo Reinado.

Na presente comunicação pretendo abordar a relação entre o grupo escultórico O Cristo e a Mulher Adúltera (1881-1884) [figura 1], de Rodolfo Bernardelli e a escultura italiana do final do século XIX, ressaltando também a importância dessa obra no cenário das artes nesse período. Esse tema foi também objeto de meu mestrado no IFCH, concluído em 20052. Para a compreensão da trajetória artística de Rodolfo Bernardelli, foi dada uma abordagem nova a essa fase da sua produção, resultando em um levantamento de materiais inéditos e até então não estudados, como pareceres e outros documentos oficiais da Academia, missivas trocadas entre os artistas e críticas de arte publicadas em jornais entre 1870 e 1885. Essa pesquisa encontra agora continuidade em meu doutorado, com enfoque na atuação do artista na direção da Academia Imperial de Belas Artes.

O grupo em mármore Cristo e a mulher adúltera, em tamanho natural, foi executado pelo escultor Rodolfo Bernardelli (1852-1931) na Itália. Entre 1877 e 1885, o jovem escultor era pensionista da Academia Imperial de Belas Artes em Roma e essa obra constituía o último dos trabalhos que deveriam ser enviados pelo aluno antes de retornar ao Brasil. A opção por Roma encontra-se expressa em vários documentos da Academia, e foi motivada provavelmente pela estada anterior de Victor Meirelles e Zeferino da Costa naquele país, e, sem dúvida, também

\footnotetext{
${ }^{1}$ Doutoranda em História da Arte pelo Instituto de Filosofia e Ciências Humanas da Universidade Estadual de Campinas.

2 SILVA, Maria do Carmo Couto da. A obra Cristo e a mulher adúltera e a formação italiana do escultor Rodolfo Bernardelli. Campinas: [s.n.], 2005. Dissertação de mestrado, IFCH/Unicamp.
} 
pela grande qualidade da escultura italiana daquele momento. Um provável divulgador no Brasil das obras dos artistas italianos foi França Júnior, que, em 1873, participou da comissão brasileira na Exposição Universal da Áustria. Em um texto de 1885 sobre Rodolfo Bernardelli, ele se refere a Giulio Monteverde, mestre de Bernardelli em Roma, destacando-o entre os valorosos artistas italianos da época:

O que é a Itália na estatuária tivemos ocasião de observar em 1873 na Exposição de Vienna de Áustria e na última Exposição Universal de Paris. O nome de Monteverde por si só foi o bastante para glorifical-a no sumptuoso torneio artístico do Prater! O famoso Pescador de Gemito e a graciosa Tufolina de Tabacchi foram os maiores sucessos do Trocadero. Com uma plêiade brilhante de escultores, entre os quaes figuram, além dos citados Dorsi, Masini, Maccagnoni e Donato Barcaglia, a Itália, essa sublime revolucionária transformou completamente as artes plásticas ${ }^{3}$.

Monteverde foi premiado nas mostras de 1873, na Áustria, e de 1878, em Paris, com Jenner que inocula a vacina em seu filho, sua escultura mais conhecida, em que está representado um médico experimentando uma vacina em seu próprio filho. Nela um assunto histórico é tratado quase como uma cena de gênero.

É importante notar, porém, que Bernardelli sempre realizou obras de um realismo moderado, como resultado do estudo com Monteverde. O realismo exacerbado de certas esculturas da época é criticado pelo artista em um manuscrito de cerca de 1877, portanto, logo depois da sua chegada na Itália:

\begin{abstract}
Visitei na Academia [ilegível], as obras modernas e tive uma desilusão por parte da minha ignorância na parte psicológica do movimento artístico, as esculturas de então faziam o possível para imitar o natural, vi umas cabeças de velhas a rir, com todas as mazelas de uma pele velha, só faltava que tivessem cabelos implantados, não gostei e externei ao prof. P. Am ${ }^{\circ}$ [Pedro Américo] que me disse ser ela a escola moderna ${ }^{4}$.
\end{abstract}

\title{
A execução do grupo “Cristo e a mulher adúltera”
}

A maquete em gesso foi aprovada pela Congregação dos Professores da Academia no começo de 1882, de acordo com as normas da instituição. Para executá-la, Rodolfo Bernardelli conseguiu a prorrogação do seu pensionato no exterior. Cristo e a mulher adúltera foi, entre os importantes trabalhos realizados em Roma por Bernardelli, aquele com qual obteve maior notoriedade em toda a sua carreira, sendo bem recebido na época pela crítica especializada, representada por autores como França Júnior, Ângelo Agostini e Gonzaga Duque. Entretanto, também para o escultor, era a obra mais significativa, a ser apresentada na Exposição de Turim, como ele próprio afirmou ao secretário da Academia, João Maximiano Mafra, em fevereiro de 1883:

(...) é necessário que eu tenha comparado minha força com a (ilegível) muitos artistas

(...) para mim só espero que a Academia me faça o favor de obter do governo mais aquele ano já porque concluirei (...) meu grande trabalho e porque poderei

\footnotetext{
${ }^{3}$ FRANÇA Júnior. Folhetins. 4.ed. Rio de Janeiro : Santos, 1926 p.556.

4 BERNARDELLI, Rodolfo. [Manuscrito]. Arquivo Histórico do Museu Nacional de Belas Artes/ Arquivo Pessoal Rodolpho Bernardelli. APO 188.
} 
apresentar-me e receber meu batismo de artista na Europa ${ }^{5}$.

Bernardelli comentava na mesma carta haver participado anteriormente de uma importante mostra italiana em 1882 com uma cabeça grande em bronze, retrato de um médico que conhecera, tratando-se provavelmente do busto de Montenovesi (c.1882). Essa obra, segundo o próprio escultor, atraiu a atenção do público e da crítica italiana. Em 1884, ele apresentou $O$ Cristo e a Mulber Adúltera na Exposição de Turim, sendo homenageado com o Grau de Cavaleiro da Coroa da Itália.

Como ressalta Celita Vacaní, o mármore utilizado no grupo, denominado Saravezza, é de primeira qualidade. $\mathrm{O}$ mesmo tipo de mármore fora empregado na cópia da Vênus Calipígia feita pelo artista em 1882. Bernardelli, em carta ao secretario da Academia Imperial de Belas Artes, João Maximiano Mafra, de 1880, fala sobre a escolha do mármore para a Vênus, que se destinava à galeria da Academia: eu entendo que o mármore deve ser do melhor, isto é, de $1^{a}$ qualidade, já pela sua cor como pela transparência e é o assim chamado Saravessa, é raro achar-se manchas; creio que a Academia terá desejo de possuir uma estátua sem defeito ${ }^{7}$. A Vênus Calipígia, segundo Bernardelli, teria destaque no acervo da Academia por ser de uma peça em mármore, enquanto as outras esculturas ali presentes eram em gesso. Bernardelli se refere então ao Cristo e a mulher adúltera, ressaltando a importância do material empregado: "No entanto, está se preparando outro mármore que irá também fazer contraste com nossos modelos de gesso" 8 .

O tema começara a ser pensado por volta de novembro de 1880. Segundo o próprio Bernardelli, o assunto fora escolhido por lhe dar maiores possibilidades de compor algo novo. Em outra carta a Mafra, ele afirmava contar em receber algum apoio financeiro da Academia, mas entendia que a sua opção pelo realismo lhe havia "adquirido antipatias" e acrescentava "eu sempre trabalhei pensando de fazer bem visto o progresso que por aqui bá, mas vejo que politicamente fir. mal'.9 O realismo presente em suas obras é muito criticado pela Academia Imperial, como é possível notar em parecer de 1882:

As duas figuras estão bem agrupadas, na atitude e no gesto são ambas perfeitamente expressivas, com boas qualidades, este grupo cuidadosamente estudado, será uma bela execução de arte estatuária (...) Pensa com tudo a seção que seria conveniente recomendar ao pensionista que na sua produção procure inspirar-se no exemplo sem conta que Roma lhe oferece da grande escola idealista: o assunto escolhido pertence por sua natureza esta escola.. 10

O esboço em gesso e a escultura em mármore pertencem ao acervo do Museu Nacional de Belas Artes, no Rio de Janeiro. No esboço, o artista ainda não havia projetado o

${ }^{5}$ CARTA de Rodolfo Bernardelli a João Maximiano Mafra, Roma, 20 fev. 1883. Arquivo Histórico Museu Dom João VI. Grifo nosso.

${ }^{6}$ Cf. VACCANI, Celita. Rodolpho Bernardelli. Rio de Janeiro: s.ed., 1949. p.83.

${ }^{7}$ CARTA de Rodolfo Bernardelli a João Maximiano Mafra, Roma, 25 jan. 1880. Arquivo Histórico Museu Dom João VI.

8 Ibidem.

9 CARTA de Rodolfo Bernardelli a João Maximiano Mafra, Roma, 25 nov. 1880. Arquivo Histórico do Museu Dom João VI.

10 PARECER sobre os trabalhos do pensionista Rodolfo Bernardelli, estudando em Roma. Rio de Janeiro, 13 jan. 1882. Arquivo Histórico do Museu Nacional de Belas Artes/Arquivo Pessoal Rodolfo E Henrique Bernardelli. APO 196. 
efeito realístico do manto, uma das qualidades mais reconhecidas da obra. Bernardelli, em carta a Mafra, afirma que ainda terá de fazer muitas mudanças na composição final, sempre procurando dar veracidade histórica à representação. Assim, afirma que a túnica do Cristo não será aquela, "ao menos prometeram-me depois que tinha concluído o trabalho de mandar-me uma túnica verdadeira, isto é, uma túnica hebraica a qual se não me engano não tem as mangas tão grandes como as que eu fiž’.11 Entre o esboço e a obra final o escultor fez algumas alterações na composição. A cabeça do Cristo foi modificada com a retirada do solidéu que a cobria. Os cabelos e a barba também foram moldados de maneira diferente. Já a adúltera é muito próxima do resultado final. As pequenas diferenças servem para revelar mais claramente o corpo da mulher, o que confere à figura uma grande sensualidade. Por exemplo, as costas da mulher, nuas, na escultura em mármore, estão parcialmente recobertas por tecido na maquete. Assim também as pernas, cobertas no esboço, revelam-se entre as aberturas do tecido na obra final.

A partir de março de 1883, o mármore para realização da escultura começou a ser desbastado por três escarpelinos, trabalhando todos os dias. Em julho, a obra ainda não havia sido concluída, havendo, segundo o próprio artista "grandíssimas dificuldades a vencer". O grupo provavelmente começou a ser executado pelo próprio Bernardelli a partir do segundo semestre de 1883. Nos vários desenhos pertencentes ao acervo do Museu Paulista, relativos ao estudo da figura do Cristo, percebe-se a preocupação do artista em trabalhar a anatomia e também em buscar a movimentação precisa dos braços e das pernas. O estudo da figura, inicialmente nua e depois vestida, foi feito em diferentes posições. Em um pequeno desenho é possível notar que o artista estudou o caimento dos cabelos em torno do rosto de Cristo. Para o manto, que aparece apenas em um dos desenhos selecionados, percebe-se que ele preocupou-se em trabalhar a textura própria do tecido e as dobras do panejamento.

\section{Modelos formais}

Um dos modelos formais para o grupo escultórico Cristo e a mulher adúltera pode ter sido uma gravura sobre o mesmo assunto, feita como ilustração [figura 2] para a Bíblia Sagrada, de Gustave Doré (1832-1883), um dos trabalhos mais conhecidos do artista francês. Para a realização das gravuras, Doré estudou diversas coleções de obras da Antiguidade, presentes em museus parisienses e empregou fotografias e vistas de Jerusalém, procurando dar às cenas grande veracidade.

Começaremos apontando algumas semelhanças formais entre a gravura de Doré referente a essa passagem da Bíblia, e a obra de Bernardelli: na atitude do Cristo, que protege com o corpo a adúltera, no longo manto que cai até os seus pés e, também, na forma como a mulher, encolhida atrás do Cristo, se protege com os braços à frente do corpo. Segundo o relato bíblico, Jesus, enquanto o inquiriam, escrevia com o dedo no chão. A inscrição concluída é apresentada na gravura e também na base da escultura, em hebraico. De forma similar, no pedestal em mármore, trabalhado com formas geométricas, podemos pensar em uma referência à coluna que se encontra no plano de fundo, na gravura. É possível notar,

\footnotetext{
${ }^{11}$ CARTA de Rodolfo Bernardelli a João Maximiano Mafra. Roma, 2 de agosto de 1881. Arquivo Histórico do
} Museu Dom João VI 
entretanto, o quanto essas obras diferem em relação à atitude das figuras. O braço estendido do Cristo à frente do corpo, com a mão aberta, assemelha-se a um gesto de pregação, o que torna a figura muito mais enfática. Já a pose da adúltera, com o rosto voltado para baixo e apoiado em uma das mãos, nos transmite uma atitude muito mais expressiva e interiorizada do que a apresentada na gravura.

É preciso ressaltar que, ao dirigir-se à Itália nesse período, entre 1878 e 1885, Rodolfo Bernardelli toma contato com uma vertente realista que se caracteriza pelo gosto pela escultura de gênero, com cenas do cotidiano, como as de crianças que brincam. Entretanto, Bernardelli não se interessa em realizar esse tipo de trabalho, voltando-se à escultura de temática religiosa. Assim, um possível modelo temático e formal para o grupo Cristo e a Mulher Adúltera pode ter sido A virgem prudente e a virgem tola (1866), do escultor italiano Giulio Monteverde. A obra foi um trabalho que Monteverde, na qualidade de pensionista da Academia Ligustica, realizou no seu primeiro ano de estudos de aperfeiçoamento em Roma, e enviou a Gênova. Ela revela grande semelhança formal com o grupo de Bernardelli, por exemplo, na posição da figura que, em pé, segura com uma das mãos um candeeiro, e da outra, agachada, que se inclina para ela em um gesto de súplica. Um dos aspectos mais evidenciados pelos críticos contemporâneos, como Vincenzo Marchese, acerca das qualidades dessa obra, é o contraste entre os corpos das mulheres: o da Virgem prudente, nobre e delicado, e o da Virgem tola, maciço e plebeu. No corpo da Virgem tola são evidentes os acentos naturalísticos e senso de vida terrena. Nesse trabalho de aluno, como aponta Francesco Prian, se prenuncia o particular modo de modelar o corpo humano que Monteverde mostrará em futuras obras cemiteriais, como no anjo da Tomba Oneto, no Cemitério de Staglieno, em Gênova. 12 Prian ressalta também que o intento ético está sempre presente na produção de Monteverde nessa época, como, por exemplo, em Jenner. Assim a obra $A$ virgem prudente e a virgem tola possui também o tema moralizante em comum com o grupo de Bernardelli.

De maneira similar, pelo uso de inscrições, e principalmente pela base do grupo escultórico, o artista mantém diálogo com obras do escultor napolitano Achille D’Orsi. Na representação de um chão árido em contraste com a maciez da carnatura dos personagens, ou na textura do panejamento, por exemplo, Bernardelli atesta afinidade com trabalhos de D'Orsi como Proximus Tuus (1880). A base incorpora-se dessa maneira à cena, ampliando o efeito realístico da composição. Tal efeito pode ainda ser visto em obras como Os parasitas (1877), de D'Orsi, ou Claudius perdoando Messalina (s.d.), de Luigi Preatoni, escultor que foi muito amigo de Bernardelli.

É importante observar que, na Exposição de Turim de 1880, o escultor Ettore Ximenes (1855-1926), apresentou um grupo escultórico com o nome de Cristo e l'adultera, da qual não foi possível obter imagem. Rodolfo Bernardelli provavelmente deve ter visitado essa exposição, já que freqüentou diversas mostras italianas e francesas nesse período. Não sabemos, entretanto, se o conhecimento dessa obra influiu na realização do seu grupo escultórico. Entretanto, na Exposição de Turim de 1884, Ximenes apresentou o grupo O beijo de Judas (c.1884) na qual a imagem do Cristo é muito próxima àquela apresentada na maquete

${ }^{12}$ Cf. PRIAN, Francesco. Giulio Monteverde, scultore. Genova: Universitá degli studi di Genova/Facoltá di Lettere e Filosofia, 1975-1976. 
do Cristo e a mulher adúltera de Bernardelli, tanto pela grande túnica que Ele veste, como pelo uso do solidéu. $\mathrm{Na}$ base da obra há uma inscrição similar ao trabalho de Bernardelli, e a cena toda transmite grande vivacidade. Há entre as obras desses dois escultores, que freqüentavam o mesmo ambiente cultural e artístico, um propósito similar de representar um Cristo humanizado.

Em nossa pesquisa, até o presente momento, não foi possível encontrar desenhos de Bernardelli referentes à figura da adúltera. Mas é possível que ela tenha sido inspirada em obras como L'Adultera, de Pietro Bernasconi, apresentada na Primeira Exposição Italiana de 1861, em que uma personagem feminina cai de joelhos sobre o solo. A grande crítica a essa escultura, conforme texto publicado no catálogo da mostra, residiu na ausência de uma segunda figura, a do Cristo, o que levaria o público a pensar na representação de qualquer adúltera, e não especificamente na passagem bíblica narrada por João.

Nos diversos textos e críticas de arte levantados em nossa pesquisa, referentes à mostra individual de Bernardelli no Rio de Janeiro em 1885, é sempre ressaltado o realismo da figura do Cristo, a dramaticidade da cena e veracidade na representação dos personagens. Assim, diversas comparações foram estabelecidas pela crítica da época entre a obra do escultor brasileiro e trabalhos de artistas europeus que também apresentaram em uma figura realista do Cristo.

Para concluir gostaria de enfatizar que o tema do grupo Cristo e a mulher aduiltera de Bernardelli convida o espectador a uma reflexão sobre o perdão dos erros, em que se aproxima do tema da escultura Santo Estevão (1879), feita anteriormente pelo artista, em que o santo injustamente condenado perdoa seus acusadores. Em sua execução, a representação de um Cristo humanizado remete aos escritos contemporâneos de Ernest Renan, em Vida de Jesus (1863), que inspirou diversos artistas italianos, como o pintor Domenico Morelli. Para Renan, Jesus se apresenta como um homem, que conhece a humanidade, e, portanto, se coloca em defesa dos pobres, das crianças, dos desfavorecidos e desprotegidos deste mundo: "vítimas da arrogância social que repele o homem bom mais humilde13" e ainda dos heréticos, dos samaritanos e dos pagãos.

Ângela Alonso, em estudo recente, ressalta que o livro de Renan causara escândalo na época: "esta descensão do deus à condição bumana era sacrilégio imperdoável para os católicos ultramontanos e ousadia festejada pelos cientistas". 14 O livro fora um sucesso de público e, em 1870, já estava na $13^{a}$ edição na França 15. Dessa forma, para a autora, os escritos de Renan difundiram no Brasil um anticlericalismo muito oportuno, em função das discussões acerca da questão religiosa brasileira. Além disso, seus escritos continham um programa de reforma social, baseado não em mudanças econômicas e políticas, como as "tentativas socialistas de nosso tempo", mas principalmente sociais, e fundamentado ainda no princípio que para se "possuir a terra é preciso

${ }^{13}$ RENAN, Ernest. Vida de Jesus: origens do cristianismo. Lisboa: Livraria Chardon, 1926. p.144.

14 ALONSO, Angela. Idéias em movimento: a geração de 1870 na crise do Brasil Império. São Paulo: Paz e Terra, 2002. p.173.

${ }^{15} \mathrm{Em} 1863$, o livro de Renan desencadeou uma tempestade sobre o autor e lhe custou a sua cadeira no Colégio de França. Apud. SODRÉ, Nelson Werneck. O naturalismo no Brasil. Rio de Janeiro, Civ. Brasileira, [1965]. (Coleção Vera Cruz, literatura brasileira, v.82). p.47. 
renunciar à terra."16 No Brasil, esse poderia ser visto como um discurso voltado às elites, mais do que às camadas populares, propondo uma reforma moral na sociedade, em tempos abolicionistas.

\section{ILUSTRAÇÕES}

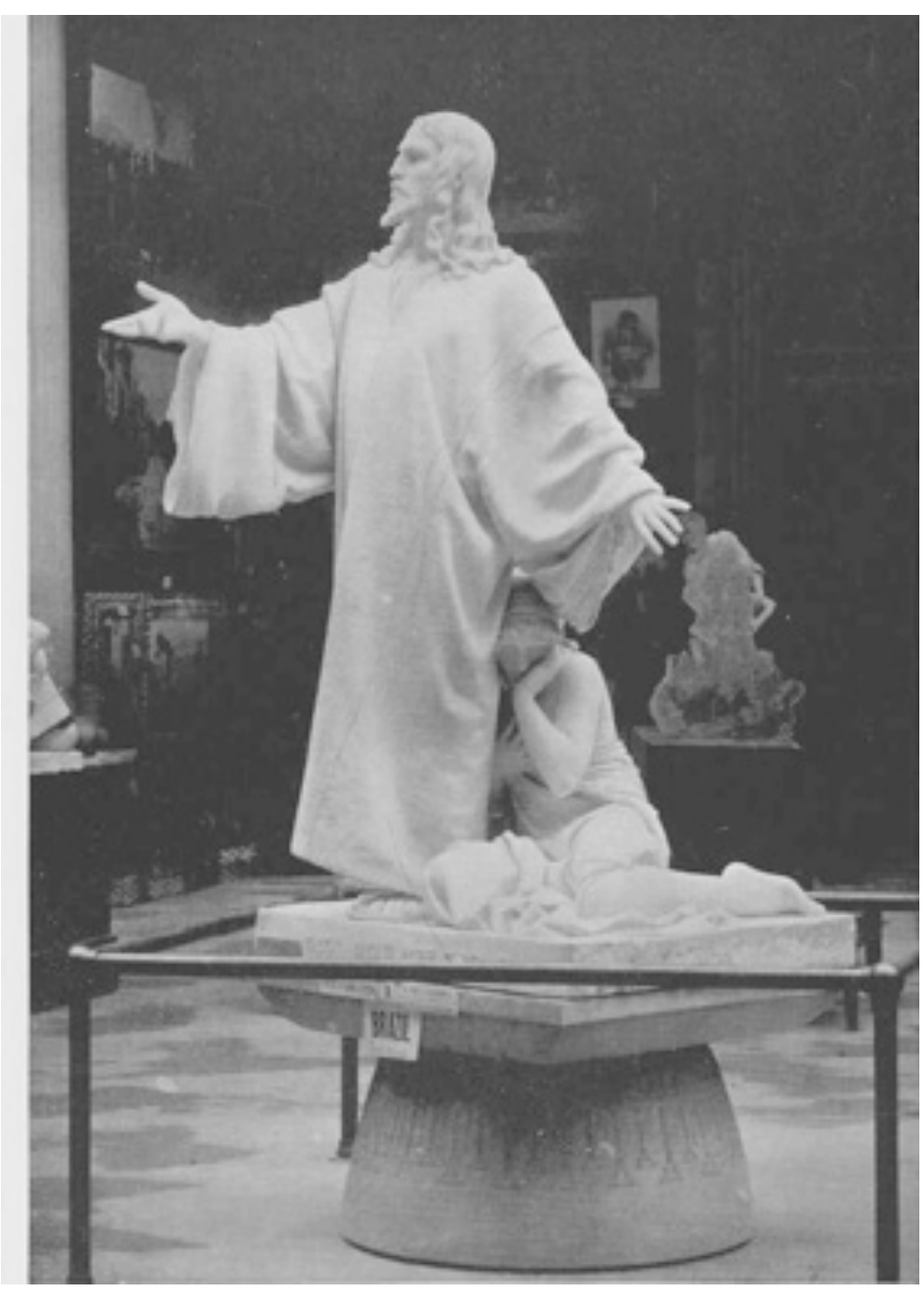

\section{Figura 1}

Rodolfo Bernardelli

Cristo e a Mulher Adúltera (1881)

Mármore, 202 x 149 x116 cm

Acervo Museu Nacional de Belas Artes, Rio de Janeiro

[Foto do catálogo da Columbian Exposition at Chicago, 1893]

${ }^{16}$ RENAN, op.cit., p.232. 


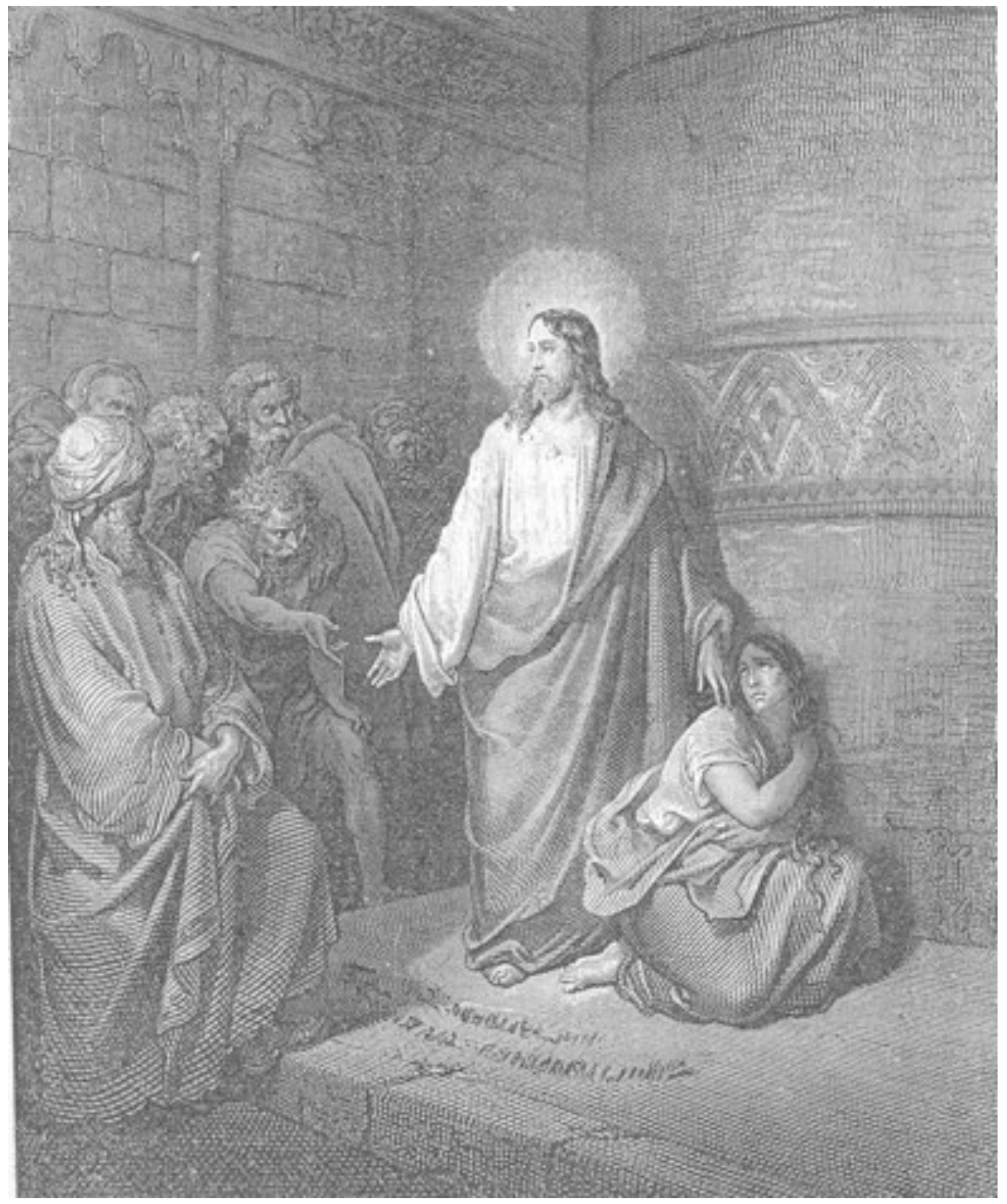

\section{Figura 2}

Gustave Doré

Cristo e a mulher adúltera (s.d.)

Extraída de La Sacra Bíblia. Milano: Fratelli Treves Editori, 1907. 